\title{
ROLAND BARTHES: UM SEMIÓLOGO NÔMADE
}

\author{
Roland Barthes: one nomad semiologist
}

Francisco Verardi Bocca ${ }^{1}$

\section{Resumo}

O presente artigo tem por encargo descrever, de maneira panorâmica, o percurso intelectual trilhado por Roland Barthes no que diz respeito às suas pesquisas na área de fundamentação e de análises semiológicas empreendidas sobre fatos culturais. Veremos, e por isso o chamamos nômade, como, tendo partido de uma adesão ao estruturalismo científico de cunho saussuriano percorreu-o aos seus limites até desembocar em sua renúncia, assumindo a análise hermenêutica como alternativa de compreensão da cultura. Para efeito de análise e ilustração, serão enfocadas algumas obras pontuais consideradas de relevância apresentadas em ordem cronológica, iniciando com Mitologias e encerrando com Aula, dando destaque para e intermediária Sistema da moda, entre outras. Esperamos com isso dar conta da construção de um roteiro confiável de sua produção intelectual.

Palavras-chave: Filosofia; Linguagem; Semiologia; Hermenêutica; Perspectivismo.

\section{Abstract}

The present article intends to describe, in a panoramic view, the intelectual trajectory of Roland Barthes in respect to his researches in the area of foundation and semiological analyses of cultural facts. We will see, and because of this we call him nomad, how, starting from an adhesion to the scientifical structuralism of saussurian character, he came to its limits until he renounced it, assuming the hermeneutical analysis as an alternative to culture comprehension. In respect to analysis and illustration, some punctual works of relevance will be focused in a chronological order, starting with Mythologies and ending with Class, and emphasizing the intermediate The fashion system, among others. We hope to build a trustable guide to his intelectual production.

Keywords: Philosophy; Language; Semiology; Hermeneutics; Perspectivism.

1 Prof. Dr. História da Filosofia Contemporânea - PUCPR

E-mail: francisco.bocca@pucpr.br 


\section{Introdução}

O propósito desse artigo é o de apresentar, evidentemente da forma restrita que este espaço admite, a evolução do conceito de semiologia, bem como da prática semiológica, de Roland Barthes, tendo como suporte teórico, digamos, sua filosofia da linguagem, apresentando-a de forma seqüencial em algumas obras que melhor evidenciam sua evolução. Quanto à imputação de uma natureza nômade para seu percurso intelectual ficará, cremos, esclarecida ao término da leitura do artigo.

Para dar início à tal apresentação assumimos estrategicamente o debate que tem sua expressão bem definida no primeiro capítulo de Introducion à la sémiologie de Georges Mounin, que apresenta uma bifurcação conceitual que nos parece de grande interesse para os estudos de diferentes sistemas simbólicos sejam lingüísticos ou extralingüísticos. São os conceitos de comunicação e de significação, que inclusive serviram de divisor de águas entre os semiólogos franceses póssaussurianos. Dada sua importância, passemos à sua consideração.

Diz Mounin (1968), segundo sua interpretação, que no Curso de lingüística geral, de Saussure, é esboçada a proposta de uma ciência geral de todos os sistemas de signos, incluindo os extralingüísticos, pelos quais os indivíduos comunicamse. Seriam estes as escrituras, o alfabeto de surdomudos, os signos militares, entre outros, que visam a uma comunicação. No entanto, Mounin (1968) adverte que as referências estendidas por Saussure aos ritos simbólicos, formas de polidez, costumes, modas, culinária, sempre despertaram muitas reservas, pois, nestes domínios, estariam contidos os germens de uma ruptura dentro do desenvolvimento de uma semiologia originalmente esboçada por Saussure, uma vez que os últimos sistemas listados apenas significam sem visar ou atingir uma comunicação, pelo menos no sentido lingüístico. Daí a distinção entre sistemas que comunicam e os que apenas significam.

Ao analisarmos a bifurcação veremos que tal preocupação para Barthes é irrelevante, pois considera que para comunicar basta significar. No interior desse ponto vista a significação recobre a comunicação, instaurando assim um ponto de vista de comunidade entre os diferentes sistemas simbólicos, o que relativiza a própria bifurcação.
Esclareçamos agora que partimos da apresentação de Mounin com o objetivo de evidenciar que, para Barthes, o que teria motivado Saussure a listar sistemas simbólicos tão díspares como os códigos militares, ritos e formas de polidez, teria sido a comparação possível de todos estes sistemas com a linguagem natural, pois a idéia básica de Saussure é que as diferentes instituições sociais como os ritos, modas, etiquetas e a própria linguagem natural, compartilham da mesma natureza: são sistemas semiológicos. A idéia é, portanto, que deve ser possível propor objetos de estudos comparáveis, quanto a serem semiológicos, à linguagem natural, sendo que esta seria o principal destes sistemas, independentemente de visarem uma comunicação estrita ou tão somente uma significação.

Assim, Roland Barthes, em obras como Mitologias de 1957 e mais tarde em Elementos de semiologia de 1964 e ainda em Sistema da moda de 1967, desenvolve a análise referente aos sistemas não lingüísticos que priorizam a "farta significação" como os mitos, a literatura, a propaganda e a moda.

Nos Elementos, Barthes (1964) fornecenos uma visão geral do campo de estudo da semiologia e dos instrumentos por meio dos quais podese realizar a pesquisa semiológica. Por intermédio desta mesma obra sabemos que em seus primórdios franceses a semiologia tinha uma dupla tarefa: de um lado propor uma teoria geral da pesquisa semiológica e de outro elaborar semiologias particulares, aplicadas a objetos e domínios como a moda, vestuário, propaganda etc. Os Elementos realizam primeira tarefa, ficando para Mitologias, Sistema da Moda e outros a elaboração de semiologias particulares.

Assumindo uma motivação saussuriana, Barthes propõe-se manejar os conceitos lingüísticos na construção de uma semiologia buscando inserir-se nesta tradição. Assim é que se vale de conceitos que já estavam definidos na ciência lingüística, como foram elaborados por Saussure. Foi nesse clima que os Elementos propuseram e organizaram um vocabulário que respaldou sua pesquisa naquele momento, o que fez desta obra um compêndio de conceituações importantes na construção da perspectiva semiológica por ele elaborada.

Sua perspectiva semiológica teve assim por objetivo qualquer sistema de signos, seja qual 
for sua substância, seus limites, imagens, gestos, inscrições, desde que constituam sistemas simbólicos. Com isso recusa a restritividade da semiologia da comunicação em favor da abrangência da semiologia da significação. Isto fica evidente em Mitologias na qual instrumentalizou os conceitos lingüísticos que poderiam fornecer-lhe uma nova perspectiva com relação aos fenômenos culturais e abraçou a possibilidade de estudar as atividades humanas como uma série de linguagens.

Nessa obra, recorreu, ainda que de maneira mais tímida, se comparada com Sistema da moda, à técnica de análise estrutural proveniente da lingüística saussuriana. Nela, seu objetivo confesso foi o de desmascarar a má fé imiscuída nos mitos contemporâneos, que devem ser pelo semiólogo expostos em seu sistema. A análise presente nesta obra, mais que semiológica, busca ser semioclasta, visa desmascarar a ideologia burguesa dos anos cinqüenta pela via da desconstrução de seus mitos.

Ocupou-se Barthes de sistemas simbólicos como a publicidade, a fotografia, vestuário de moda, entre outros, manifestando interesse de ordem pessoal por sistemas cuja construção não foi presidida pela intenção primeira de comunicar uma mensagem determinada, mas que, contudo, significam. No entanto, não o fez de forma homogênea em toda sua carreira e nosso propósito aqui é, de início, o de demonstrar que trilhou de início os passos do estruturalismo, como proposta de alcançar pelo sentido os códigos implícitos nos sistemas simbólicos, para, por fim, desembocar em uma hermenêutica, isto é, em uma interpretação dos fatos simbólicos sem os recursos estruturalistas.

Deve ficar claro também que Barthes, em cada fase, teve uma concepção própria de semiologia, isto é, inspirado em Saussure, formulou teorias semiológicas com as quais orientou sua pesquisa. A verificação e o acompanhamento destas concepções compõem o interesse desse artigo, onde suas fases, bem como suas obras de maior importância e contribuição para nosso propósito serão visitadas. Passemos a elas.

\section{Mitologias: primeiras práticas semiológicas}

A fase de Mitologias foi propriamente aquela em que Barthes reconheceu como legítima a proposta saussuriana de que a lingüística, que toma a linguagem natural por tema, seria futuramente uma parte da ciência geral dos signos quando esta viesse a se constituir. Uma vez tendo admitido a possibilidade de uma ciência que demonstre com seu exemplo o caráter sistêmico dos demais fatos simbólicos, Barthes adotou sem problemas a supremacia da semiologia sobre a lingüística. Posição da qual se desvencilhou mais tarde (1957).

Quanto a essa obra, trata-se sem dúvida de um trabalho militante, engajado, onde recorreu aos procedimentos de análise legados pela lingüística. Apesar do recurso à lingüística, não podemos dizer que tenha tratado explicitamente o mito contemporâneo, ou a fala mítica, como o chamou, como a linguagem natural, pois reconhece nessa ocasião que o mito depende de uma semiologia, ciência esta extensiva à própria lingüística.

$\mathrm{O}$ que queremos esclarecer com a insistência em apontar para a supremacia da semiologia sobre a lingüística é que, nestas circunstâncias a linguagem natural funciona como inspiração de sistemas ordenadores das diferentes linguagens. Por enquanto, estabeleçamos que desde já cabe à semiologia, segundo Barthes, explicar as leis que regem os signos dos diferentes sistemas simbólicos. Claro está que inclusive os mitos contemporâneos passam a ser um tema da vasta ciência semiológica, com o que fazer semiologia dos mitos é estudar sua significação enquanto sistema simbólico.

Por influência da indicação de Saussure, no conceito barthesiano de mito, encontramos o mesmo esquema presente no signo lingüístico. No entanto nem por isto pode-se dizer que a significação do mito se reduz à do signo lingüístico. Antes se trata de um sistema com características bem particulares. Comecemos por defini-lo.

$\mathrm{O}$ uso do termo mito designa para Barthes uma falsa evidência, isto é, ele é pensado inicialmente em seu sentido literal, de mentira, de falsa realidade, como alegoria, como forma figurada, por fim como representação de algo para dar idéia de outro, constituindo, portanto, uma linguagem. Essa perspectiva permite defini-lo inclusive como uma fala. Assim sendo deve haver condições especiais para a elaboração de um mito, isto é, de uma mensagem falada, já que nesses termos ele nada mais é do que um modo de significação, em duas palavras, uma forma.

Na perspectiva que vem sendo definido, o mito é para Barthes uma forma de operação e 
não uma substância. Logo qualquer conteúdo ou substância pode ser transformado em mito. Acrescente-se que, para ele, não há mitos eternos, já que é a história que transforma o real em mito. Isto quer dizer que para ele, "é a história que comanda a vida e a morte da linguagem mítica" (BARTHES, 1957, p.132). Nesses termos é que nos faz entender que o suporte do mito é a história, a experiência vivida, podendo ser, digamos, qualquer uma, desde que permita ser utilizada para uma nova significação.

Com isso ele quer dizer que a fala mítica "é formada por uma matéria já trabalhada em vista de uma comunicação apropriada" (BARTHES, 1957, p.132). No entanto lembremos, não se trata de uma matéria qualquer nem indiferente. Sua matéria deve ser, e o é, em algum aspecto imperativa, impõe uma significação. Esse ponto de vista permite-nos concluir que a significação mítica deve postular uma relação entre dois termos, um significante e um significado, que apesar de serem matérias de diferentes ordens, e por isto não constituem uma igualdade, devem pressupor ao menos uma certa equivalência.

$\mathrm{O}$ que foi anunciado no parágrafo anterior fica melhor explicado quando entendemos que, por não ser a significação mítica imotivada, ela não relaciona arbitrariamente os seus termos, antes relaciona-os por algo de comum que se impõe, isto é, a preexistência significativa de um termo deve conter ou fornecer um elemento ao menos que sirva ao interesse da nova composição, isto é, do signo mítico. A essa altura, carecemos de uma exposição mais esquemática do conceito e do esquema de funcionamento do mito, passemos a ele. $\mathrm{O}$ mito é constituído, reiteremos, a partir de uma matriz que, diferentemente da língua, já é uma cadeia semiológica particular, que já era semiológica antes de passar a fazer parte do mito, de compô-lo, o que alça o mito à condição de sistema simbólico de segunda ordem.

Assim, quer seja a linguagem natural, quer as imagens ou objetos em geral que sirvam de base ao mito, o que interessa destes é apenas a função significante que possam exercer, isto é, a função de significante que ocupam no mito. Tal função é ocupada pelo que foi designado por Barthes como "linguagem-objeto". Para ampliar sua compreensão apresentemos seu esquema como formalizado por Barthes (1957), para em seguida comentá-lo, conforme esquema abaixo:.

\begin{tabular}{|c|c|}
\hline $\begin{array}{l}\text { QUADRO } 1 \text { - Título } \\
\text { 1- significante } \\
3 \text { - signo }\end{array}$ & ificado \\
\hline $\begin{array}{l}\text { SENTIDO } \\
\text { I - SIGNIFICANTE } \\
\text { FORMA }\end{array}$ & $\begin{array}{l}\text { II- SIGNIFICADO } \\
\text { CONCEITO }\end{array}$ \\
\hline $\begin{array}{c}\text { III - SIGNO } \\
\text { MITO }\end{array}$ & \\
\hline
\end{tabular}

Fonte: Mitologias, p.137.

Em termos descritivos, o esquema acima quer dizer que o signo que era terceiro termo do primeiro sistema passa a atuar como significante (primeiro termo do segundo sistema ou segunda ordem) no produto final que passa assim a relacionar-se com novo significado (segundo termo da segunda ordem), compondo o mito ou signo da segunda ordem.

Segundo o esquema, como vimos, o que passa a ser significante no mito (segundo sistema) era signo no primeiro sistema. Este, que já era dotado de uma história, na segunda participação revela, participa e contribui com apenas parte dela. Nesses termos é que se pode dizer que o segundo sistema afasta ou deforma toda riqueza do signo do primeiro sistema.

Em termos mais explícitos, no mito, que não é definido como um objeto ou idéia, mas um modo de significação, o significante é tomado ou como termo final do sistema de onde saiu ou como termo inicial do sistema mítico onde adentrou. Quanto ao significado no mito, este recebe de Barthes em acréscimo o nome de conceito. Por sua vez, o terceiro termo completando o sistema é a própria significação mítica.

Nos termos em que está sendo definido, o conceito de mito exige mais esclarecimentos. Digamos que de maneira geral o mito é tomado por uma "palavra", uma "comunicação" e constitui uma mensagem. $\mathrm{O}$ que incomodou Barthes, nessa constatação, foi o fato de ser ele a deformação de um sentido histórico a serviço de uma ideologia. Assim é que podemos entender como uma composição do tipo de uma estrela vermelha, por exemplo, precisa abdicar consideravelmente de sua condição geral de signo para compor uma pretendida 
mensagem, digamos sumariamente de "guia da luta operária”, sua significação mítica.

Na mesma obra, a título de dar consistência à exposição do esquema semiológico do mito, Barthes comenta uma manchete de jornal tomando-a como uma construção mítica e explicitando sua estrutura. A manchete compunha-se dos seguintes dizeres: "Preços começam a ceder. Legumes: primeira baixa". Para Barthes, essa manchete corresponde a uma mitificação na medida em que pode ser compreendida como um significante que mantendo sua forma tem seu sentido pleno esvaziado e reaproveitado apenas parcialmente, isto é, em sua porção que permite compor, segundo sua análise, um significado ou conceito de governabilidade. Assim, o produto da mitificação ou sua significação final pode ser compreendida, segundo relata Barthes, como uma baixa de preços provocada pelo governo, por atuação e mérito deste.

O que, parece-nos agora evidente, não é senão parte de um dos sentidos possíveis do significante mítico (a manchete), a parte que convinha à ideologia do jornal que a publicou ou do jornalista que a elaborou. Seu desvelamento corresponde assim ao trabalho do mitólogo. Para exemplificarmos e ampliar ainda mais a compreensão do que está sendo chamado de "palavra mítica", recorreremos a um dos principais exemplos dado por Barthes (1957) em Mitologias. Trata-se da análise da publicidade do sabão em pó Omo. Nessa análise Barthes aponta para a penetração que o detergente, pela via da publicidade maciça, exerceu na vida cotidiana dos franceses. Assim, é a estratégia e a armação montada pela publicidade que Barthes visa esclarecer.

Para isso parte de uma comparação das soluções de cloreto de sódio (cândida) com o detergente em pó Omo. Diz ele que os primeiros "foram sempre considerados como uma espécie de fogo líquido cuja ação deve ser controlada, sem o que o próprio objeto pode ser queimado" (BARTHES, 1957, p.29), produzindo assim, continua ele na mesma página, "uma modificação violenta, abrasiva da matéria: tais produtos matam a sujeira". A comparação, continua ele, tem o propósito de destacar que de fato "ao contrário, os pós são elementos separadores: o seu papel consiste em libertar, expulsar a sujeira sem provocar "morte"”. As cenas da propaganda mostram a sujeira (representada por um pequeno inimigo débil e negro) fugindo e assim evitando o contato com o deter- gente, o que resulta numa roupa branca porque livre da sujeira.

Com esses recursos são atribuídos aos pós-detergentes características de "seletivos, empurram e conduzem a sujeira através da trama do tecido, desempenhando uma função de policial e não de militar" (BARTHES, 1957, p.29). Por essa ação liberam a dona de casa consumidora do produto de uma ação mais laboriosa e cansativa. Ao apontar para esse processo Barthes mostra a ação e a intenção desejada pela publicidade que está embutida.

Ainda na linha da revelação dos mecanismos da publicidade, Barthes apontou a utilização das noções de profundidade e de espumoso. Nesta, Barthes aponta o recurso à espuma produzida pelo detergente como elemento e fator de um tipo especial de limpeza desejado pela publicidade. O elemento espuma, utilizado para obter tal resultado, apresenta um significado que, segundo Barthes, é de conhecimento e domínio de todos, isto é, num primeiro momento a espuma é historicamente associada ao luxo, podendo ser também associada a uma imagem de proliferação farta, evidenciando a abundância de elementos presente numa porção mínima do sabão utilizado, o que permite supor um produto poderoso e concomitantemente delicado, já que espiritualizado pela espuma.

Ora, a construção do mito ocorre, na concepção de Barthes, na medida em que o publicitário, tomando a forma e o sentido descritos da espuma como significante associado ao estado de espiritualidade que tradicionalmente a acompanha como seu significado, utiliza-a como elemento significante de um novo sistema, por isso chamado de segunda ordem. Barthes (1952, p.32) aponta para a construção do mito, ou sistema de segunda ordem, mostrando como a espuma que "pode ser o signo de uma certa espiritualidade na medida em que considera o espírito capaz de tirar tudo do nada", passa a ser no mito (ou na publicidade) significante de uma nova mensagem, agora visando esconder a ação abrasiva do produto comercializado.

O sentido da primeira significação é, como ele diz, "esvaziado" e tomado como forma, como significante, para na nova composição ser associado a um novo conceito. Nesse caso, o consumidor é predisposto a imaginar uma relação saudável e eficiente entre o detergente e o tecido que o rece- 
beu. Dessa forma o publicitário consegue esconder a verdadeira atuação de qualquer detergente que é a de ser abrasivo, "sob a imagem deliciosa de uma substância simultaneamente profunda e aérea, que pode reger a ordem molecular do tecido, sem a atacar" (BARTHES, 1957, p.30). Isso quer dizer que o mito, repitamos, toma como significante (e esvazia-o) o que já era (em outra cadeia semiológica) signo. Assume assim o papel de metalinguagem, já que o mito associa o signo esvaziado (agora tomado como significante) com um novo significado ou conceito, obtendo dessa operação o que chamou de significação mítica. A relação entre as duas partes é que constitui a significação, o terceiro termo.

Nesses termos, é-nos adequado concluir pela existência de um sistema simbólico constituído desempenhando o papel de linguagem objeto para a metalinguagem que é o mito. Deve ficar claro que esse sistema que serve de linguagem objeto para o mito não é unicamente constituído de palavras, mas também de gestos, fotos, desenhos etc., desde que possam percorrer os dois sistemas semiológicos, isto é, ocupar lugares e funções diferentes em ambos os sistemas, seja o de primeira ou de segunda ordem.

Os parágrafos anteriores também tiveram por meta mostrar o quanto Barthes relaciona o signo lingüístico com os signos dos demais sistemas simbólicos, ainda que não esteja, pelo menos de maneira explícita, pleiteando absoluta similaridade. Queremos deixar claro que o que está sendo tomado por linguagem objeto independentemente de ser constituído de palavras, gestos, fotos, entre outros segue sempre um esquema lingüístico, isto é, está sempre descrito e compreendido segundo uma conformação "similar" ao signo lingüístico, analogamente. Isso nos faz concluir que Barthes julgou a teoria saussuriana dos signos lingüísticos como suficientemente geral para explicar com os seus esquemas o funcionamento dos signos próprios dos demais sistemas simbólicos.

Retomando, digamos que o mito aparece como um construto em benefício de uma intenção ideológica. Sua ocultação intencional, nos alerta Barthes, tem por objetivo naturalizar o signo, darlhe a aparência de naturalidade, como se a imagem (de uma propaganda) provocasse desintencionalmente o conceito. Assim podemos dizer que a função do mito é deformar e não fazer desaparecer o sistema de base, já que o conceito mítico deforma no significante mítico não a sua forma, mas o seu sentido.

A essa altura uma questão se impõe. Dessa riqueza do signo de base e de seu conseqüente esvaziamento o que restará e por quê? Em outras palavras, o que justificaria a permanência desta e não de outra parte do sentido manipulado que permanecerá à disposição do criador de mitos para alimentar a pretendida significação de segunda ordem? Responderemos que a escolha se dá pela conveniência. Algo é emprestado visando a uma conveniência.

Daremos continuidade à nossa argumentação por via de uma outra questão que decorre do esquema de significação do mito. Diz Barthes que o conceito obtido no sistema mítico é, por assim dizer, "constituído por associações moles, ilimitadas. É preciso insistir sobre este caráter aberto do conceito (mítico); não é absolutamente uma essência abstrata, purificada, mas sim uma condensação informal, instável, nebulosa, cuja unidade e coerência provém sobretudo de sua função" (1957, p.141). Essa observação refere-se diretamente aos modos de reenvio, de relacionar a forma e o conceito mítico. Deve-se dizer mais uma vez que aqui ressalta a motivação que preside esse sistema. Digamos que, ao contrário da linguagem natural, que é arbitrária e imotivada como já vimos, a mítica "não é nunca completamente arbitrária, é sempre em parte motivada, contém sempre uma analogia" (BARTHES, 1957, p.147). Sua significação precisa sempre de uma analogia tanto na forma quanto no sentido.

Por seu turno na significação mítica, nada se apresenta completamente arbitrário, reconhece Barthes. O mito é em grande parte motivado, 0 significante é motivado pelo conceito que representa. Essa motivação, que pode ser analógica, é assim sustentada apesar de o conceito mítico ter à sua disposição uma massa de significantes possíveis que exemplifiquem a mesma coisa. Isto quer dizer que a motivação pode ser exercida dentre várias possibilidades sem que por isso venha a ser considerada arbitrária. Por exemplo, o conceito de "imperialidade francesa" obtido na capa da revista Paris-Match citada em Mitologias, poderia bem ser atingido, como sugere Barthes 91957, P.148), pela imagem de "um professor francês branco dando aulas a jovens negros atentos". Ou ainda outros.

Fica claro que apesar de o conceito mítico poder realizar-se em inúmeros significantes e 
de ele próprio não guardar nenhuma essência, podendo constituir-se, alterar-se ou desfazer-se, a motivação é necessária à própria duplicidade do mito; este joga com a analogia do sentido e da forma. Barthes afirma que: "não existe mito sem forma motivada" (1957, p.147).

Por exemplo, sugere Barthes, um conjunto de objetos desordenados pode oferecer à interpretação a desordem, pode conferir uma significação ao absurdo, isto é, fazer do absurdo um mito. Ele faz-nos ver que a analogia entre o conceito e 0 sentido míticos é sempre apenas parcial, assim como também a forma do significante mítico pode conservar apenas alguns traços analógicos. Essa afirmação ficará melhor explicitada quando analisarmos em capítulo futuro alguns sonhos e sintomas obsessivos em que essa formulação se evidencia. Mas o que nos interessa em particular é que a motivação do mito proporciona sempre uma escolha entre várias possíveis.

Fica assim evidente que o esquema do mito evidencia sua função. Mais uma vez diremos que é a de promover deformações, isto é, em sua terminologia, "transformar um sentido em forma" (BARTHES, 1957, p.152). Já quanto ao seu aspecto de natural-mascarado deturpando a realidade, Barthes declara que na condição de semiólogo quer "recuperar o abuso ideológico que na minha opinião nele se dissimula" (BARTHES, 1957, p.7). Para isso, Barthes procurou captar significações de segunda ordem já que o mito contemporâneo é um modo de promover significações, associações de um significante a um significado sobrecarregado de ideologias.

Somente a análise semiológica do mito permite descobrir o "código" dessa linguagem. Por oposição à linguagem mítica, Barthes oferece-nos uma focalização analítica desmistificadora do mito, que busque uma melhor compreensão das significações míticas desmascarando-as, com o que se passa da situação de leitor ou consumidor do mito à de mitólogo. Para isto, faz-se necessário focalizar no mito "o significante pleno, no qual distingo claramente o sentido da forma, e portanto, a deformação que um provoca no outro" (BARTHES, 1957, p.149). Assim procedendo destrói interpretando-a, a significação do mito, recebendo-a como uma impostura, para usar sua terminologia. Segundo Barthes "este tipo de focalização é a do mitólogo que decifra o mito e compreende uma deformação" (1957, p.149).
Com isso, Barthes descreve claramente as condições que permitem ou possibilitam a produção de signos de segunda ordem ou sistema mítico fartamente veiculado nos meios de comunicação e também uma proposta de focalização do mito a encargo do semiólogo que chamou de análise semiológica. Quanto à primeira descrição, nada temos a acrescentar, já quanto à segunda, cumprenos verificar em que medida coaduna-se com a proposta semiológica saussuriana. Verificação que faremos no próximo tópico.

\section{O realce da lingüística}

Numa leitura de Elementos, publicação cronologicamente posterior a Mitologias, deparamos com o argumento de Barthes quanto à necessidade de generalizar o método lingüístico, de aplicá-lo para além dos estudos habituais concernentes à lingüística.

De início, sempre tomando Saussure por base, Barthes efetiva a extensão da lingüística relativamente aos diferentes sistemas simbólicos. Com isso, começam a aparecer as divergências em relação a Saussure, pois este pensava e várias vezes o disse, ser a lingüística uma parte da ciência geral dos signos. Apesar disso, Barthes rebate, argumentando que em nossa vida social contemporânea não há outro sistema de signos com a mesma amplitude que a linguagem natural. Também acrescenta que a linguagem natural funciona como intérprete dos demais sistemas simbólicos e que a palavra pode ser tomada como substituta de toda e qualquer ordem significante, com o que, qualquer empresa semiológica deve levá-la em consideração.

Um destaque dessa monta dado à linguagem natural leva-nos a concluir que em sua concepção todos os sistemas simbólicos, de maneira geral, não são suficientemente autônomos para constituírem-se sem o apoio da linguagem natural, isto é, para ele todo sistema simbólico só se torna semiológico quando filtrado pela linguagem natural e nunca o inverso. Confirmando esse posicionamento, Benveniste diz-nos que "toda semiologia de um sistema não lingüístico deve pedir emprestada a interpretação da língua, não pode existir senão pela e na semiologia da língua; instrumento de análise" (BENVENISTE, 1974, p. 63). Aqui a linguagem natural é tomada como uma or- 
ganização semiológica por excelência, dando a idéia de que é a fórmula exemplar de modelagem semiológica.

Com isso, o que fica claro em sua obra seguinte, que é Sistema da moda, é que de uma fotografia, por exemplo, só pode ser feita semiologia se explicada com o recurso da linguagem natural. Percebe-se que o sustentáculo de sua prática semiológica passa a ser a relação que se estabelece entre o lingüístico e o não lingüístico. Supondo esta inter-relação é que Barthes fará semiologia da moda, no caso, do figurino de moda.

Foi observando fatos culturais como o cinema, publicidade, história em quadrinhos, fotografia de imprensa, entre outras manifestações culturais, que Barthes constatou o que identificou como uma dependência desses gêneros em relação à linguagem natural. Percebeu que as imagens não podem dispensar a escritura, que nessa ótica é realçada à condição de fundamento das imagens. O que equivale a dizer que uma substância visual confirma sua significação quando, digamos, repetida lingüisticamente. Mais tarde, veremos, no prólogo de Sistema da moda, a linguagem natural ser identificada e definida não apenas como modelo de significação, mas inclusive e principalmente, como seu fundamento.

É importante que destaquemos tais concepções, pois marca a evolução de seu conceito de semiologia, bem como seu procedimento como semiólogo, distinguindo-o do Barthes que conhecemos em Mitologias. Diz ele em 1964, nos Elementos que, apesar de todos os avanços em todas as áreas da cultura, permanecemos uma civilização da escrita. Essa idéia o penetrou com tal força que acabou por influenciar sua própria concepção de semiologia e do objeto de análise, que assim perde sua autonomia diante da linguagem natural. Por conta disso a semiologia estaria fadada a "absorver-se numa translingüística", declara Barthes já na introdução dos Elementos, pois só reconheceu o estatuto de sistêmico aos diferentes conjuntos de objetos ou fatos humanos, quando esses "pela mediação da linguagem natural tivessem seus significantes denominados sob a forma de nomenclaturas e também tivessem seus significados denominados sob a forma de usos ou razões" (BARTHES, 1964, p.12).

Nos termos em que foi recolocada por Barthes, a semiologia ou ciência geral dos signos passa a ser uma parte da lingüística no sentido de dela depender seu exercício, apesar do semiólogo não necessariamente ocupar-se de substâncias lingüísticas. $\mathrm{O}$ encontro com a linguagem natural é considerado desde agora inevitável, pois, como vimos, esta assume a responsabilidade pelo estatuto sistêmico dos fatos não lingüísticos. Por conta disso, a semiologia passa a ser a análise do discurso escrito, no caso de Sistema da moda, sob o qual fatos simbólicos significam, isto é, recebem significação.

Com isso, "a matéria da semiologia será o mito, a narrativa, o artigo de imprensa, os objetos de nossa civilização desde que sejam falados..." por meio da imprensa, do prospecto, da legenda. (BARTHES, 1964, p.13). O saber semiológico passa a ser um tipo de cópia do saber lingüístico, a reboque deste. Nesse sentido é que, para Barthes, a lingüística é que passa a ser a ciência geral dos signos e a semiologia uma parte dela, a que cuidaria das unidades simbólicas do discurso. Mais tarde, apenas adiantando, Barthes irá decretar, fazendo juz ao seu nomadismo, o divórcio entre sua semiologia e a lingüística.

Com os argumentos até aqui apresentados, Barthes justificou sua primeira posição de desacordo em relação a Saussure. Inclusive sua observação quanto à dificuldade de um sistema de imagens ou objetos ter seus significantes existindo totalmente fora do alcance da linguagem natural retira destes sistemas sua condição de autonomia, isto é, de terem do interior de seus próprios sistemas a produção de seus significados ou conceitos. Ao contrário, Barthes diz que um conjunto de objetos só alcança o estatuto pleno de sistema quando repassado pela mediação da linguagem natural e quando identificado com ela enquanto sistema. Por fim diz ele que "a lingüística não é uma parte, mesmo privilegiada, da ciência geral dos signos mas a semiologia é que é uma parte da lingüística, ou seja, a parte que encarrega-se das grandes unidades significantes do discurso" (1964, p.13).

Ao estender dessa forma a lingüística saussuriana aos demais sistemas simbólicos, Barthes estava, parece-nos, querendo encontrar tão somente as condições para que pudesse pensar diferentes sistemas simbólicos sob o rigor de um pensamento científico. Estava, portanto respondendo ao desafio de pensar uma ciência rigorosa dos fatos humanos. Consideremos como motivador dessa iniciativa o fato de que o método lingüístico apre- 
sentava-se, ou era considerado na época, como rigoroso e científico, provavelmente devido aos avanços que apresentava em relação às demais ciências humanas. Assim, o pretenso estruturalismo de Barthes na década de sessenta do século vinte seria como uma forma de analisar artefatos culturais com os métodos e, principalmente, com a terminologia lingüística, o que constitui uma tentativa, como já dissemos, de abordagem de caráter sistemático e rigoroso dos fatos culturais.

Quanto aos fatos culturais analisados, a moda ocupou lugar de destaque por sua importância no contexto da época. Com respeito a isso discorreremos mais detidamente no próximo tópico, sobre o plano de análise elaborado e utilizado por Barthes (1967) em Sistema da moda. Assim, teremos a oportunidade de conhecer mais profundamente uma análise semiológica particular e de melhor analisar seu posicionamento, nesse caso, relativamente à concepção saussuriana de semiologia.

\section{A moda como semiologia particular}

Após 1964 quando publicou Elementos, Barthes deu aos seus estudos um novo rumo, procurou realizar o que chamou de crítica ou desmistificação sistemática das ideologias que motivam as produções culturais. O que nos permite identificar essa fase como um avanço relativamente às análises, como dissemos acima, empreendidas em Mitologias. O ganho sistemático referido fez de Sistema da Moda uma obra declarada por ele de cunho e inspiração estruturalista.

Sua investigação nessa obra concentrouse, por opção metodológica, na descrição verbal apresentada em publicações de moda. Nessas circunstâncias é que o vestuário foi determinado como campo de pesquisa semiológica. A empresa consistiu em analisar "estruturalmente" o vestuário feminino a partir das publicações de moda. Com o que já considera o vestuário real, as roupas enquanto tais, como um sistema de signos impotente para constituir sozinho a sua significação.

Pelas razões já expostas, aplica a análise a um certo número de enunciados verbais responsabilizados pela significação do vestuário, pois nessa ótica o vestuário real só vai adquirir sua significação plena quando traduzido em vestuário descrito. $\mathrm{O}$ que na verdade percebe-se é que sua empresa não se ocupa nem mesmo do vestuário, nem mesmo da linguagem natural, mas da tradução que a linguagem natural faz do vestuário.

Ocupou-se assim de publicações de moda, em especial de revistas como "Elle" e "Jardin des Modes" entre outras como "Vogue" e "Echo de la Mode". Nessas análises percebe-se claramente a circunstância em que é realizada a reversão do postulado saussuriano, pois se presencia claramente o semiológico como um transbordamento do lingüístico, o que faz da linguagem natural, não somente o modelo da significação, mas também 0 seu fundamento, pois é a linguagem natural que vai permitir a reflexão sobre o sentido da moda.

Observa Barthes (1967, p.262) o fato de que a multiplicação e enraizamento do hábito de leitura das publicações de moda nas sociedades européias contemporâneas modificou o fenômeno da moda, transformou-o em fenômeno cultural provido de uma estrutura original. O trabalho da linguagem natural é o de interferir nessa estrutura "simples", multiplicando-a em "mil espécies significantes", constituindo o sentido em sua plenitude.

Para Barthes, a ação das palavras superestima as possibilidades semânticas do vestuário real, principalmente do vestuário fotografado, que é comentado em forma de legendas. Assim é que ocorre uma atuação no intuito de produzir significados, uma vez que o vestuário real não oferece sentidos senão em níveis rudimentares, como exemplifica Barthes: "tecidos leves em relação a tecidos pesados" (1967, p.261). O enunciado encontrado nas publicações constitui um sistema de significações composto de um significante, que é ele próprio e de um significado, que é a moda. Juntos compõem uma unidade de significação.

Ora, Barthes toma assim o vestuário escrito como exemplo sistemático de signos e de regras da moda. Para ele o vestuário escrito é uma língua em estado puro, já que nunca corresponde a uma execução individual das regras da moda, pois "a língua da moda não emana da "massa de falantes", mas de um grupo de decisão, que elabora voluntariamente o código" (1964, p.28). Assim, tomando por significante do código vestuário todo enunciado que a publicação de moda dedica ao vestuário, Barthes procura neles descobrir uma forma constante e diz: "do contrário, não se saberá nunca como o sentido vestimentário (que é a moda) será produzido" (1967, p.57). 
A análise sobre os enunciados seguiu duas exigências metódicas sugeridas por Barthes: primeiramente "dividir o enunciado em espaços tão reduzidos quanto possível, como se todo enunciado de moda fosse uma cadeia na qual importa localizar os elos", em seguida "comparar entre si estes fragmentos de espaço, de maneira a determinar segundo que oposições eles produzem sentidos diferentes" (1967, p.57).

Depois de termos apresentado as indicações do procedimento de Barthes, passaremos a apresentar, a título de exemplo, a análise (um fragmento dela) que realizou sobre o corpus estudado nas publicações de moda. Nessa Barthes elabora uma classificação de sessenta gêneros relativos às espécies levantadas no inventário das publicações. Citaremos apenas alguns para não sobrecarregar a exposição e também por julgarmos suficiente para os comentários posteriores.

\section{GÊNEROS ESPÉCIES}

$\begin{array}{ll}\text { ACESSÓRIOS } & \text { (bolsa, luvas, bolsinho etc..) } \\ \text { LGADURA } & \text { (fivelas, gancho, alfinete etc..) } \\ \text { COLAR } & \text { (corrente, cordão etc..) } \\ \text { CALÇADOS } & \text { (botas, polainas, chinelos etc..) } \\ \text { MOTIVO } & \text { (xadrez, mesclado, florido etc..) } \\ \text { VESTIDO } & \text { (tubinho, uniforme etc..) } \\ \text { MATERIAL } & \text { (couro, tecidos, palha etc..) }\end{array}$

Nesses termos, a tarefa do semiólogo é dupla, isto é, deve em primeiro lugar assumir a lógica da pesquisa que é inventariar e classificar. Contudo, a etapa posterior, que seria a de elaborar modelos, não foi realizada por Barthes, questão que será mais adiante explicitada.

Em resumo, em Sistema da moda a descrição lingüística é que vai explicitar a significação dos diferentes sistemas simbólicos. Claro que também aqui, pelo que foi apresentado, diverge da noção saussuriana de sistema, da combinatória autônoma e abstrata concebida por Saussure. Tais observações serão melhor explicitadas no próximo tópico.

\section{Uma reflexão sobre o que foi dito}

Comecemos investigando qual a pertinência da dedução da natureza dos signos extralingüísticos a partir do signo lingüístico que Barthes opera em Sistema da Moda. Trata-se de in- vestigações pertinentes, pois, ao termos presenciado o trabalho de Barthes desde Mitologias, vimos que nela considerou a primeira ordem do sistema mítico como de natureza lingüística, isto é, tomou os diferentes sistemas simbólicos que servem ao mito como compartilhando e apresentando "comportamentos" e "esquemas" do signo lingüístico. Nessa concepção, a linguagem-objeto que serve ao mito estaria sendo compreendida e definida pela teoria lingüística do signo e não por uma teoria do signo em geral.

A prática barthesiana parece-nos estar assim "mesclando", sob a mesma teoria dos signos, aqueles que são naturalmente imotivados (os lingüísticos) e os motivados (por exemplo, os mitos contemporâneos). Muito provavelmente por ocasião dessa mescla, vê-se que já em Elementos Barthes anuncia e posteriormente em Sistema da moda adota a consideração de que a teoria do signo lingüístico aplica-se à análise semiológica de diferentes sistemas desde que estes estejam repassados pela linguagem natural. Com isso e por isso, passa a realizar em Sistema da moda, como vimos, análises dos discursos proferidos na descrição lingüística de sistemas simbólicos em geral.

Parece procedente inserir aqui uma crítica feita por Giles Gaston Granger (1950) no capítulo $\mathrm{V}$ da obra Linguagem e epistemologia, onde considera abusiva a aplicação da noção de língua a propósito de qualquer sistema simbólico, de qualquer fato cultural, pois em verdade, considera que tais fatos possam existir enquanto sistema, mas alerta que seus signos nem por isso podem sempre ser chamados saussurianos. Isso pelo fato de o valor dos signos extralingüísticos não ser neles só negativo ou opositivo, como no signo lingüístico.

Reconhece Granger que, muitas vezes, as propriedades de uma língua são atribuídas sem problemas a sistemas onde não se aplicam sem problemas, isso pelo simples fato de diferentes sistemas serem tomados como linguagens, em função do que se está, por equívoco ou precipitação, emprestando a diferentes sistemas a forma de uma língua. Trata-se justamente do alerta que procuramos fazer relativamente à particular concepção e prática semiológica de Barthes.

Por isso, a crítica de Granger parece-nos pertinente, pois realça a impropriedade de se tomar a linguagem natural como protótipo de sistemas simbólicos em geral, ainda que estejamos autorizados a tomá-la como sistema simbólico por 
excelência, justamente em virtude de sua complexidade estrutural, já apontada por Saussure e não por apresentar traços elementares e fundamentais que compreendam toda ordem simbólica.

Ainda nessa crítica, deixemos claro que Barthes não está fazendo uma descrição da estrutura do "costume-signo", mas, sim, do "costumediscurso". Essa troca de papéis pode levar à confusão ou identificação do sistema simbólico da moda, longe de ser um sistema estruturado como a linguagem natural, com o seu reflexo lingüístico. Contudo, devemos reconhecer que esta transfiguração, desde que consciente e explícita, pode assumir uma certa importância para a descrição e explicação de diferentes fatos simbólicos.

Após termos criticado a intenção de Barthes de extrair da ciência lingǘstica um instrumental suficientemente válido para o exercício da pesquisa semiológica, reconheçamos que o recurso aos esquemas lingüísticos teve por objetivo permitir análises bem mais sistemáticas. Ainda a propósito do recurso que Barthes fez aos esquemas lingüísticos vale verificar os impasses e as justificativas de sua proposta de estruturação semiológica a partir do binômio língua/ fala. Nossa intenção nesse caso fica sendo a de saber se a utilização que fez dos conceitos lingüísticos como língua/fala (ao considerar o vestuário descrito, por exemplo, como uma língua em estado puro), não passa de uma ornamentação de sua prática de escrita sobre moda, publicidade e outras coisas.

O binômio lingüístico foi utilizado, destaquemos, como se reproduzisse uma possível estrutura binária do sistema que descreve. Tal conceito reconhecidamente presente na linguagem natural, é apontado por Barthes como igualmente presente na moda, na alimentação, enfim, nos diferentes "sistemas" que a linguagem natural descreve. Assim podemos criticar Barthes, por ter chamado o vestuário descrito de uma língua em estado puro, justamente quando nos parece uma impropriedade. Sabemos que um sistema, como o que se referiu, que seja elaborado a partir de um grupo de decisão jamais poderia ser assimilado à noção saussuriana de sistema. A "língua" do vestuário descrito é justamente, como descrita, marcada pelo aspecto da motivação e de um tipo de convencionalismo, características que negam todo o princípio de autonomia do sistema, proposto por Saussure.

Contudo, utilizações conceituais desse tipo pareceriam reduções ingênuas da parte de
Barthes, se não houvesse o propósito de garantir o rigor, ou seja, a isomorfia dos conceitos transpostos de um sistema para outro. Felizmente, Barthes refere-se ao par língua/fala, como sendo um instrumento ou uma categoria, que se pensaria ser suficientemente geral para permitir e viabilizar a preparação da pesquisa semiológica em diferentes campos. Com essa correção, Barthes nos faz ver que a reunião desses conceitos não garante necessariamente sua subsistência no decurso da pesquisa. De fato, Barthes mostra-nos que nem mesmo a semiologia deve ou deverá sempre seguir estritamente o mesmo modelo, com o que reconhece que um possível "desvio" ou uma possível "adaptação" das prescrições saussurianas, não corresponderia a um abandono da construção da ciência semiológica, nem mesmo motivo para alterar-lhe o nome.

Segundo estas últimas argumentações que aparecem claramente já nos primeiros capítulos dos Elementos conceitos como língua/fala, significante/significado, seriam, digamos agora, apenas princípios de classificação que permitiriam a introdução de uma ordem inicial na massa diversificada dos fatos culturais, podendo tais princípios ordenadores permanecerem sempre provisórios ou substituíveis. Assim, ao postular a existência de uma categoria geral língua e fala extensiva a todos os sistemas de significação ele o faz reconhecendo que "na falta de algo melhor, conservaremos aqui os termos língua e fala, mesmo que não se aplicarem a comunicações cuja substância não seja verbal" (BARTHES, 1964, p.28). Identificamos nessa citação uma nítida declaração de independência intelectual, conceitual e metodológica, por conta do que Barthes manteve sempre a marca de quem estava iniciando, criando propriamente uma atividade intelectual.

Continuando nessa linha de raciocínio, Barthes diz ainda: "vimos que a separação entre língua e fala constitui o essencial da análise lingüística; seria vão, pois, propor logo de saída esta separação para sistema de objetos, imagens ou comportamentos que ainda não foram estudados sob um ponto de vista semântico. Podemos, somente para alguns dos sistemas propostos, prever que certas classes de fatos pertencerão à categoria língua e outros à categoria fala, dizendo logo que, nesta passagem semiológica, a distinção saussuriana está exposta a modificações, as quais cumprirá precisamente observar" (1964, p.28). 
Por enquanto, com vistas nas justificativas acima apresentadas, parece ficar claro que Barthes não estava e nem nunca esteve incorrendo em uma precipitação ou ingenuidade, antes esteve sempre consciente das dificuldades teóricas de postular uma prática semiológica onde conceitos são por hora utilizados e não construídos. No entanto, não por ignorar as incompatibilidades, mas por acreditar nas possibilidades, manteve, por algum tempo, o "sonho" de poder analisar estruturalmente fatos sociais. Análise que, respaldada na "cientificidade" do método adotado, estaria, por assim dizer, conferida de autenticidade, podendo com segurança explicitar códigos, os que respaldariam as ideologias da sociedade burguesa de sua época, da qual sempre foi crítico ferrenho.

Por fim, lembremos que tratamos nesse tópico do uso que Barthes fez da noção saussuriana de língua. Para concluir, lembremos que o "sonho" a que nos referimos, mantido até Sistema da moda, acabou por ser deixado de lado por Barthes, recusando o estruturalismo e distanciando-se da lingüística e de seus conceitos. A fase pós-estruturalista de Barthes merece de nossa parte especial atenção por constituir uma nova perspectiva semiológica, por isso lhe dedicaremos 0 tópico a seguir.

\section{O pósestruturalismo de Barthes}

Até aqui, presenciamos um Barthes com pretensões estruturalista, desejoso de instituir uma semiologia de cunho científico com métodos e resultados rigorosos. Foi com essa perspectiva que pretendeu extrair sentidos, desmontar significações, atingir códigos que organizam fatos simbólicos, explicando seu funcionamento. Supôs até então que a explicitação dos códigos pudesse conferir autenticidade a uma análise, ficando claro que tal concepção de ciência e de rigor sempre correspondeu à concepção saussuriana de ciência.

Nessa prática incorreu até optar por uma hermenêutica ou interpretação dos fatos, abandonando a idéia de promover uma análise científica sobre o funcionamento dos sistemas simbólicos em geral, ou seja, rejeitando a idéia saussuriana de uma ciência estrutural dos signos. Por ocasião dessa nova postura, isto é, de uma fase onde as fronteiras entre estruturalismo e semiologia começam a ganhar novo aspecto, que é crescente ao longo dos anos e das obras, encontramos um Barthes que considera sistemas simbólicos sob nova ótica. Trata-se de manter a noção de que fatos simbólicos possam ainda constituir sistemas, mas que produzem sentidos intermináveis.

Essa é uma abordagem seminal para sua nova concepção de semiologia, pois além de atenuar a noção de sistema, altera sua expectativa em relação aos sistemas extralingüísticos. Claro que alterando igualmente sua concepção de ciência e de rigor, o que procuraremos demonstrar apresentando conceitos como código, sistema, estrutura, metalinguagem e hermenêutica, que sofreram modificações em seu novo percurso de semiólogo-hermeneuta. Certamente Barthes avançou em seu percurso consciente e determinado a não mais fazer ciência como um dia pretendeu, contudo sabendo que conduzia a investigação dos signos até onde esta pudesse estender-se. Comecemos por reconhecer que foi por conta de tais mudanças que sua semiologia deixou de ser um ramo da lingüística, pois o fato cultural semiológico, nessas circunstâncias, deixou progressivamente de ser pensado como sistêmico, ao menos em termos de uma isomorfia com a língua saussuriana.

Rompe com a submissão à lingüística, uma vez que deixa de privilegiar a linguagem natural relativamente a outros fatos simbólicos, como se a estivesse destituindo do alto posto que ocupou na hierarquia dos sistemas simbólicos. É certo que estamos diante do nascedouro de uma nova concepção de semiologia. Se antes a idéia de uma ciência abrangente desempenhava um papel importante para sua tendência estruturalista, depois de $S / Z$, quando passou a ser visto como pós-estruturalista, a noção de rigor científico foi substituída pela de "interpretação possível", ou ainda, de um "amplo questionamento". Passou Barthes a praticar um amplo questionamento com o objetivo de produzir análises reveladoras do funcionamento dos fatos simbólicos, fazendo destes o que podemos livremente chamar de leituras interessantes.

Sua nova postura foi mais radical no que diz respeito ao rompimento com o passado do que parece à primeira vista. $\mathrm{O}$ fato simbólico passou a ser visto como uma precária arquitetura de figuras sem ordem, ou, para sermos menos contundentes, de uma ordem fluida, isto é, um conjunto fértil e interminável de ângulos e lugares. Passou a recusar para os fatos simbólicos analisados qual- 
quer redução a fronteiras bem definidas e delimitadas; recusa a existência de uma causa eficiente, de um sistema subjacente presidindo-os. A partir de S/Z, ou ainda nesta obra, deixou de realizar a quebra do texto em busca de códigos, inaugurando como dissemos sua fase pós-estruturalista, com a renúncia ao código, onde os diferentes aspectos do sentido passaram a ser explicados aplicando-lhes a hermenêutica, a interpretação como recurso.

Com o que foi dito até agora, relativo ao pós-estruturalismo de Barthes e de sua identificação da semiologia com a hermenêutica, cremos ser imprescindível procedermos a uma análise das obras que nos apresentam o novo Barthes, sua nova concepção, como prometido acima, dos conceitos propostos como código, estrutura, sistema simbólico e análise semiológica. Trata-se das obras S/Z, Fragmentos de um discurso amoroso e Aula. Nestas, o abandono do estruturalismo de inspiração saussuriano, bem como do desígnio de cientificidade prognosticado pelo estruturalismo lingüístico ficam bem representados. Nestas recolheremos brevemente as caracterizações desejadas para a exemplificação de sua nova concepção semiológica.

Uma vez percorridas as obras mencionadas, poderemos, de forma mais segura, concluir pela identificação já anunciada da semiologia com a hermenêutica. Isto será de grande valia para compreendermos sua concepção semiológica mais madura. Feito isso, estaremos aptos a compreender a própria ruptura ocorrida no interior das práticas semiológicas de Barthes. Passemos a elas.

\section{A hermenêutica como nova fase da semiologia}

Trataremos aqui inicialmente de uma análise textual da obra Sarracine de Balzac, levada a cabo por Barthes em S/Z, onde o S representa 0 escultor Sarracine e Z o personagem Zambinella. O próprio título, no que tem de pouco esclarecedor sobre o conteúdo da obra, já é um convite a que se invista em diversas interpretações possíveis em sua leitura. A obra total constitui um exame semiológico de um texto clássico. Trata-se de um tipo de metodologia aberta de leitura de texto que chamaremos de "plural", o que procuraremos explicar nos parágrafos seguintes.
Dessa obra tentaremos retirar e expor a noção de hermenêutica, por isso extrairemos, em forma de citações, não propriamente exemplos da análise que elabora da obra de Balzac, mas as justificativas teónicas de seu novo ponto de vista. Nessa obra, a própria análise é uma leitura e sua operação já é toda a pesquisa do sentido, onde será necessário meios para reconhecer este sentido. Para isso, consideramos que é necessário definir, segundo Barthes, a própria operação de leitura, o que faremos recorrendo a uma citação: "Ler, com efeito, representa um trabalho de linguagem. Ler é encontrar sentidos e encontrar sentidos é denominá-los; mas estes sentidos denominados são levados a outros nomes; os nomes se atraem, reunem-se e seu agrupamento leva-nos a mais uma vez se fazer designar..." (BARTHES, 1970, p.17).

Com isso, não podemos considerar, segundo Barthes, o ato de ler como o de simplesmente colocar o leitor diante de um texto, pois o leitor, colocado diante dele, já é ele próprio "outro texto", outros e infinitos códigos, novos códigos e discursos. Essa multiplicidade ou pluralidade, segundo a qual o leitor é concebido, permite a Barthes atingir múltiplas possibilidades, isto é, o leitor é enquadrado dentro de uma prática de leitura onde o conceito de verdade é dela suprimido, pois tanto a leitura como a releitura podem e, neste caso, têm por finalidade "multiplicar os significados, e não chegar a um significado final qualquer determinado" (BARTHES, 1970, p.17).

Quanto ao texto, Barthes reconhece igualmente seu "plural", ou seja, o texto é tido como uma galáxia de significantes e não uma estrutura de significados. Entendemos que o texto de leitura é idealmente plural, não tem propriamente começo e além de tudo é reversível, diz Barthes, "a ele se tem acesso por diversas portas, nenhuma das quais pode ser com segurança declarada principal" (Barthes, 1970, p.11). Do ponto de vista metodológico, o plural do texto acarreta uma importante conseqüência: "nada de construção do texto, tudo significa constantemente e por diversas vezes, mas sem delegação a um grande conjunto final, a uma estrutura derradeira" (Barthes, 1970, p.18). O leitor, em sua concepção, traça ao longo do texto zonas de leituras a fim de nelas observar a migração dos sentidos e 0 aflorar dos códigos.

Como se vê, já nessa obra Barthes não mais pretendeu manifestar estruturas, mas produ- 
zir, na medida do possível, uma "estruturação" que só podemos agora conceber como um trançar de códigos envolvidos circunstancialmente na leitura do texto. Advirtamos que o que aqui ainda está sendo chamado de código nada mais pode ser do que algo sem contorno fixo e definido, algo que desperta interesse justamente por não poder ser assumido por alguém, a não ser pelo leitor que os elabora a partir de sua relação com o texto.

Nessa perspectiva acaba por romper definitivamente com o modelo lingüístico de análise, uma vez que, como vimos, prioriza o comentário relativo às variações dos elementos do texto, deixando de buscar suas relações constantes. Essa renovação trouxe consigo mudanças na terminologia e no instrumental conceitual empregado, mas verdadeiramente o que caracteriza a mencionada ruptura é a recusa da busca de um significado ou sentido determinado em uma estrutura subjacente.

No que diz respeito à recusa da busca de uma estrutura subjacente, a leitura que empreende deixa de ser o resultado de uma postura metodológica visando a um questionamento do sentido intrínseco, produzido nas relações recíprocas entre os elementos de uma estrutura subjacente. A análise semiológica passa a ser o saber que o leitor ativo pode obter a partir de seu relacionamento com o texto, que, nestas circunstâncias, Barthes o chamou de "implícito e irrecuperável". O legado maior de S/Z foi, nesse sentido, a compreensão de que o significado de uma obra nunca é preenchido pelo próprio texto, antes pelos que o lêem.

A reformulação em sua concepção semiológica que é o que nos interessa, faz-se também presente em Fragmentos de um discurso amoroso. Ocupou-se Barthes do discurso amoroso alegando indiferença e abandono que o mundo contemporâneo lhe impôs. Ele foi, no argumento de Barthes, deixado de lado pela ciência, pelas artes e precisa por isso de uma afirmação. Essa obra não contém uma metalinguagem, não é propriamente uma análise sobre o discurso amoroso, antes é um discurso, digamos sucintamente, apresentado por uma pessoa fundamental que é o "eu", o que enuncia o discurso, o sentimento.

Ao ter reconhecido no prólogo de Fragmentos que o discurso amoroso tem sido excluído de áreas como as artes e a ciência, Barthes propôs, não lhe estender estas áreas, mas dar-lhe uma afirmação, adotando o princípio de que "não é preciso reduzir o enamorado a uma simples cole- ção de sintomas, mas sim fazer ouvir o que há de inatual na sua voz, quer dizer, de intratável" (BARHTES, 1977, p.l). Assim, Barthes substituiu a "descrição do discurso amoroso" por uma simulação que representou um "pôr em cena uma enunciação e não uma análise". Para isso adotou o que chamou, na obra, de figuras ou frações de discursos captados intuitivamente. A escolha, a definição ou o destaque dessas figuras ou fragmentos do discurso estão apoiados no que se pode chamar de feeling, um guia que é o sentimento amoroso de cada um.

Por exemplo, nessa obra destaca e apresenta uma figura que chamou angústia, sobre a qual não elaborou uma definição, mas um argumento no sentido de ter sido simplesmente exposto ou inventado. Barthes justifica-a a pretexto de preenchê-lo e destacá-lo. Vejamos como opera: "Angústia: O sujeito apaixonado, do sabor de uma ou outra contingência, se deixa levar pelo medo de algum perigo, de uma mágoa, de um abandono, de uma reviravolta, sentimento que ele exprime sob o nome de angústia." (BARTHES, 1977, p.22). Ora, esse tema (da figura angústia) existe, porque em algum lugar alguém o sente e exclama-o.

Para demonstrar o caráter aleatório do que chamou de figura, Barthes define seu arranjo da seguinte maneira: "as figuras surgem na cabeça do apaixonado sem nenhuma ordem, porque dependem cada vez de um acaso, nenhuma lógica os liga nem determina sua contigüidade" (BARTHES, 1977, p.4). Por fim reconhece que para compor as diferentes figuras, nomeá-las e escolher fragmentos, recolheu trechos de diversas origens como leituras regulares, ocasionais, conversas com amigos e das suas próprias vivências.

O discurso amoroso, como Barthes o concebeu nessa obra, está longe de ser considerado um aglomerado de sintomas que requeira uma investigação em busca de sua causa eficiente ou motivadora. Trata-se, arriscaremos dizer, de um lugar cujos contornos são imprecisos e, por conta disso, extensivo ao âmbito da parole e dotado de uma langue (se houver) muito tênue e de apreensão escorregadia. O discurso amoroso é, nesse enfoque, a-taxiológico e injustificável relativamente a um ponto fixo que lhe sirva de referência.

$\mathrm{O}$ aspecto que fica bastante claro na leitura de Fragmentos é o desinteresse de Barthes em deter ou reter o significado, mas antes em 
fundá-lo, isto é, não existe nele a preocupação de explicar possíveis sentidos gerados a partir de uma rede abstrata de elementos opositivos, mas apenas de engendrá-los e inaugurá-los relativamente à riqueza que o texto literário, enquanto material significante, apresenta. A produção de sentidos ou significados, aqui assume ares de subjetividade. Não se trata, pelo que vem sendo dito, de uma metalinguagem, mas de uma linguagem primeira, ou melhor, uma linguagem adjunta que cria o sentido, pois diante do texto o leitor é também escritor, ou ainda, reescritor do texto.

A, podemos agora chamar, análise-comentário, longe de empregar uma linguagem que incide sobre um fato simbólico visando construir (abstrair-lhe) um modelo que o represente é, antes, vista aqui como uma extensão da própria atividade criadora inicial, como uma prática que visa, ao tomar um fato, incrementar-lhe os sentidos, ampliar suas possibilidades significativas, explorar sua potencialidade simbólica. Quando concebemos aqui o movimento de produção de sentidos, como advindo da própria atividade semiológica, acabamos (por influência de Barthes) de apreciar seu movimento de recusa de toda e qualquer pretensão à objetividade, à obtenção de um sentido obtido por abstração.

Reitere-se que a recusa da semiologia como metalinguagem, já presente nessa obra, é a rejeição de considerá-la como uma linguagem exterior à linguagem que supostamente descreve. Ao assim conceber, retira a possibilidade de uma caracterização científica para a atividade semiológica, como, reiteremos, uma atividade distanciada que oferece uma descrição de sistemas simbólicos por meio de modelos abstratos.

Muito provavelmente estamos agora em condições bastante satisfatórias para compreender o que foi dito acima da prática semiológica de Barthes, como sendo uma "leitura interessante", uma "interpretação possível", ou ainda, um "amplo questionamento". Uma leitura que antes de tudo deixa de ser metalinguagem passando a ser uma linguagem produtora de sentidos, o que para Barthes pode representar um "ganho" do hermeneuta, que faz uma leitura valorizante do vivido, sobre o semiólogo estruturalista. Registre-se que a recusa da metalinguagem em benefício da linguagem produtora de sentidos guarda o ponto de inflexão principal da carreira de Barthes.

\section{Conclusão}

Uma conclusão sempre suscita uma retrospectiva relativamente àquilo que se quer concluir. Assim, lembremos que a semiologia barthesiana nasceu de seu inconformismo diante, digamos, da má-fé presente nos mitos contemporâneos, descritos em Mitologias, contra os quais Barthes colocou seus préstimos de semiólogo, entendido naquela ocasião, por ele, como mitoclasta ou semioclasta.

Definida por Saussure como a ciência geral dos signos, estava a semiologia ligada intrinsecamente à lingüística. Tal concepção, aceita inicialmente por Barthes, conduziu-o ao norteamento de suas pesquisas relativas aos fatos simbólicos pela via do estruturalismo. Motivação que alimentou em Elementos de semiologia e Sistema da moda.

Sua postura inicial, em legitimar-se como saussuriano, logo se mostrou vacilante. Acrescentemos agora que na célebre exposição oral, sua aula inaugural da cadeira de semiologia literária do Colégio de França, pronunciada em 1977, três anos antes de sua morte, posteriormente publicada com o título de Leçon, Barthes reconheceu ter relacionado sua pesquisa, desde o início, ao nascimento e desenvolvimento da semiologia estruturalista. Reconhece também que sua tendência a deslocar seus conceitos básicos (da semiologia) retirou-lhe a condição de representante da ciência saussuriana. Nessa mesma ocasião, definiu a semiologia que se propunha a lecionar como uma atividade que, longe de negar o signo, "nega que seja possível atribuir-lhe caracteres positivos, fixos, a-históricos, a-corpóreos, em suma, científicos" (BARTHES, 1977, p.37).

Em outras palavras, Barthes define a semiologia negando-lhe a condição de chave de leitura dos fatos simbólicos, isto é, de instrumento que permitiria a apreensão laboriosa destes. Nega-lhe agora a possibilidade ou tarefa de abstratamente construir sobre os fatos simbólicos sistemas de regras que os tornem inteligíveis por esta via. Diz ele que, quanto aos fatos humanos, a semiologia deve buscar "soerguê-los em certos pontos e em certos momentos" (BARTHES, 1977, p.39). Tratar os fatos humanos dessa maneira constitui uma prática longínqua do abstracionismo científico proposto por Saussure.

Ora, a conseqüência dessa concepção é que a semiologia não pode ser ela própria meta- 
linguagem, pelos motivos já expostos anteriormente e particularmente porque a atividade semiológica remete-se a signos com o auxílio de signos, o que torna inadequado conceber a exterioridade de uma linguagem em relação à outra.

Por fim, podemos dizer que não há mais em sua perspectiva a busca de estruturas abstratas a serem reconhecidas, que não há mais busca de um sentido proveniente de um sistema autônomo. Há sim a busca de um sentido que, sem ser convencional, sem se apoiar em códigos explícitos, é definido subjetivamente, circunstancialmente e historicamente. Em função disso, podemos dizer que ocorre igualmente uma relativização da distinção saussuriana de língua/ fala.

Assim, a semiologia de Barthes, \$eixa de postular o papel de uma ciência autônoma, como queria Saussure. Antes, deve ela ser auxiliar das demais disciplinas. O semiólogo seria, respaldado por uma nova filosofia da linguagem, muito mais um artista do que um cientista que compreende a evidência do signo que lhe salta aos olhos.

Por conta de sua concepção atual de semiologia, Barthes, radicalizando, recusa-lhe inclusive a denominação de hermenêutica e justifica em Leçon, dizendo que "ela pinta mais que perscruta" (BARTHES, 1977, p.40). Dissemos tratar-se da recusa de uma caracterização da semiologia como hermenêutica, quando esta é ainda definida como procedimento de estudo, de sondagem, de indagação ou investigação que vise a produzir deciframentos e apresentar resultados sistemáticos. Quer com isso recusar uma identificação de sua semiologia com todo e qualquer método que possa ser considerado heurístico, isto é, um método para o descobrimento de verdades.

Com isso, Barthes quer atribuir à sua semiologia apenas o caráter de uma leitura valorizante do vivido. Assim, apenas na medida em que a hermenêutica possa ser abstraída de qualquer resquício de sistematicidade, disciplina e rigor, pode ser identificada com sua semiologia. Esta recusa implica, como dissemos, abandonar a pretensão estruturalista que visa a descobrir estruturas (no caso de um estruturalismo ontológico) ou mesmo construí-las (no caso de um estruturalismo metodológico).

Agindo assim, Barthes, como vimos, substituiu o pólo da permanência pelo pólo do devir, o que não caracterizou uma simples e ingênua negação do estruturalismo. Apenas abandona a pes- quisa das formas ou modelos explicativos dos fatos humanos, passando a reconhecer e privilegiar a historicidade da investigação que, na nova perspectiva, coloca-se permanentemente em marcha. Nosso autor afirma com sua atitude a possibilidade de que, por atos de "invenção", significados sejam permanentemente elaborados.

Apresenta Barthes uma nova visão de um mundo que contém apenas um grau muito tênue de organização. Tênue, no sentido de que tem criado "a cada vez" os objetos de que carece e os mecanismos ou formas de organizá-los. Queremos dizer que tal perspectiva insere-se no que Umberto Eco chamou de Obra aberta, isto é, de uma obra que elabora seu código (que não a precede), que o funda a partir de si mesmo, que oferece a chave de sua própria leitura. A perspectiva de Barthes passa a ser a de uma atividade que, longe de visar a descobrir estruturas, visa a construir ad infinitum novas realidades, novos simbolismos onde sua pesquisa, homologamente ao processo de produção, já é atividade produtora de formas e de significados.

Por fim, cremos ter apresentado o percurso evolutivo das concepções e práticas semiológicas de Barthes, justificando o nomadismo que lhe atribuímos no título desse artigo.

\section{Referências}

BARTHES, R. Mitologias. São Paulo: Difel, 1957. trix, 1964.

Elementos de semiologia. São Paulo: Cul$\overline{1967 .}$

O Sistema da moda. São Paulo: Edusp, S/Z. Paris: Seuil, 1970.

Fragmentos de um discurso amoroso. São Paulo: Francisco Alves, 1977.

Aula. São Paulo: Cultrix, 1977. teira, 1980.

A câmara clara. São Paulo: Nova Fron-

BENVENISTE, E. Problemas de lingüística geral II. São Paulo: Pontes, 1974.

DE SAUSSURE, F. Curso de lingüística geral. São Paulo: Cultrix, 1915. 
DE MAURO, T. Cours de linguistique générale. Paris: Payot, 1972.

ECO, U. A estrutura ausente. São Paulo: Perspectiva, 1976.

Tratado de semiótica geral. São Paulo: Perspectiva, 1980.

Obra aberta. São Paulo: Perspectiva, 1968.

GRANGER, G.G. Lógica e filosofia das ciências. São Paulo: Melhoramentos, 1950. $\overline{\mathrm{eck}}, \overline{1} \overline{\mathrm{T}} \overline{\mathrm{g}}$.

Langage et epistemologie. Paris: Klincksi-
Língua e sistemas formais. In: SUMPF, J., GRANGER, G.G., BOUVERESSE, J. GAUVIN, J. Filosofia da linguagem. Coimbra: Almeida, 1973.

Formes, opérations, objets. Paris: Philosophique J. Vrin, 1994.

MOUNIN, G. Introdução à lingüística. Lisboa, 1968. nuit, $\overline{1} \overline{9} \overline{7}$.

Recebido em 15/10/2003

Aprovado em 20/12/2003 